\title{
Identifying Potential Active Species in Au/ZnO CO Oxidation Catalysts
}

Q. He,* A. Thomas, ${ }^{* *}$ J.K. Edwards, ${ }^{* *}$ A.F. Carley, ${ }^{* *}$ G.J. Hutchings, ${ }^{* *}$ and C.J. Kiely*

* Department of Materials Science and Engineering, Lehigh University, Bethlehem, PA 18015-3195, USA

** Cardiff Catalysis Institute, School of Chemistry, Cardiff University, Cardiff, CF10 3AT, UK

The low temperature oxidation of $\mathrm{CO}$ to $\mathrm{CO}_{2}$ is a key reaction in the field of gold catalysis, not only because it represents Haruta's historic discovery of unexpected room temperature catalytic activity in nano-crystalline gold [1], but also because it is a commercially important reaction in fuel cell technology [2]. Gold supported on zinc oxide has been proven to exhibit good catalytic activity and stability for the $\mathrm{CO}$ oxidation reaction [3]. However numerous studies have as yet failed to conclusively reveal the identity of the catalytically active species in the $\mathrm{Au} / \mathrm{ZnO}$ system [4].

The aim of this work is to understand the nanostructure-performance relationships that exist for the $\mathrm{Au} / \mathrm{ZnO}$ catalyst system. State-of-the-art electron microscopy techniques have been used to characterize a systematic series of $\mathrm{Au} / \mathrm{ZnO}$ catalysts made by a simple co-precipitation method [3]. The set of catalysts were calcined over a range of different temperatures (i.e. dried at $110{ }^{\circ} \mathrm{C}$ only, calcined at $200,250,300,350$, and $400^{\circ} \mathrm{C}$ ) for a 4 hour-period. As shown in Fig. 1, the calcination temperature employed had a profound effect on the resultant catalytic performance, with those materials calcined at $250-300^{\circ} \mathrm{C}$ exhibiting the best $\mathrm{CO}$ conversion after 60 minutes on-line.

Conventional bright field and phase contrast lattice imaging was effective for following the changes in $\mathrm{ZnO}$ grain-size and morphology over this temperature range, as shown in Fig. 2. In addition, it was possible to characterize the Au particle size distribution by these methods, provided that the metal particles were greater than $1 \mathrm{~nm}$ in size. However the use of aberration corrected high angle annular dark field (HAADF) imaging [5] has now clearly shown that the nature of the gold distribution on $\mathrm{ZnO}$ is far more complex than previously imagined. So far, five distinct gold morphologies have been identified by STEM-HAADF to co-exist on these $\mathrm{ZnO}$ supports; namely (i) isolated $\mathrm{Au}$ atoms, (ii) sub-nm Au clusters, (iii) ordered monolayer rafts of Au atoms, (iv) linear stripes of $\mathrm{Au}$ and (v) epitaxial Au nano-particles greater than $1 \mathrm{~nm}$ in diameter, as shown in Fig. 3. Interestingly, the estimated number fraction of these five distinct Au species is observed to vary with calcination temperature of the $\mathrm{Au} / \mathrm{ZnO}$ catalyst. In this presentation, we will describe our efforts to deduce the relative catalytic activities of these various forms of supported gold by correlating the measured catalytic activity with catalyst nanostructure.

References

[1] M. Haruta et al., Chem. Lett. (1987) 405.

[2] P. Landon et al., J. Mater. Chem. 16 (2006) 199.

[3] S. Al-Sayari et al., Top. Catal. 44 (2007) 123.

[4] G.J. Hutchings, Dalton Trans. (2008) 5523.

[5] A.A. Herzing et al., Science 321 (2008) 1331. 


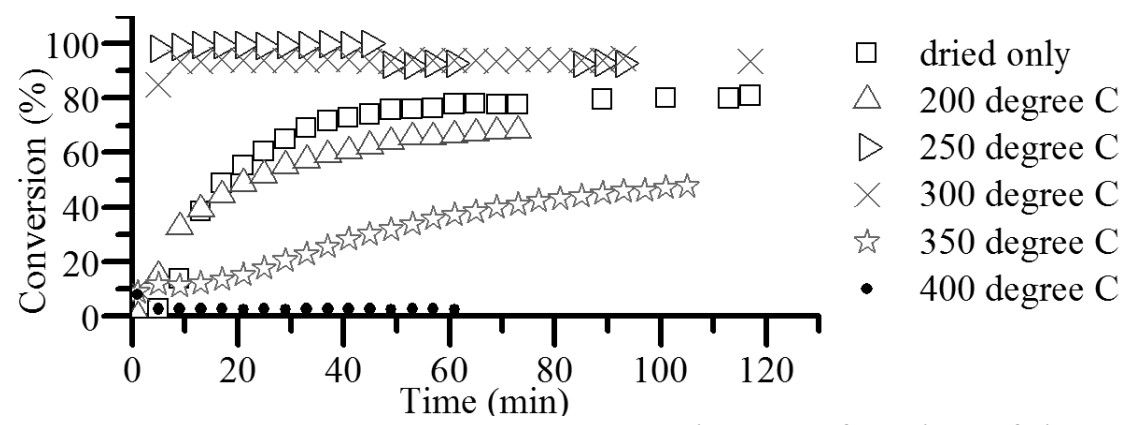

FIG. 1. Room temperature $\mathrm{CO}$ conversion as a function of time-on-line for a series of $5 \% \mathrm{Au} / \mathrm{ZnO}$ catalysts: reaction conditions, $\mathrm{CO}$ flow rate $21.4 \mathrm{ml} / \mathrm{min}$, catalyst mass $50 \mathrm{mg}$.

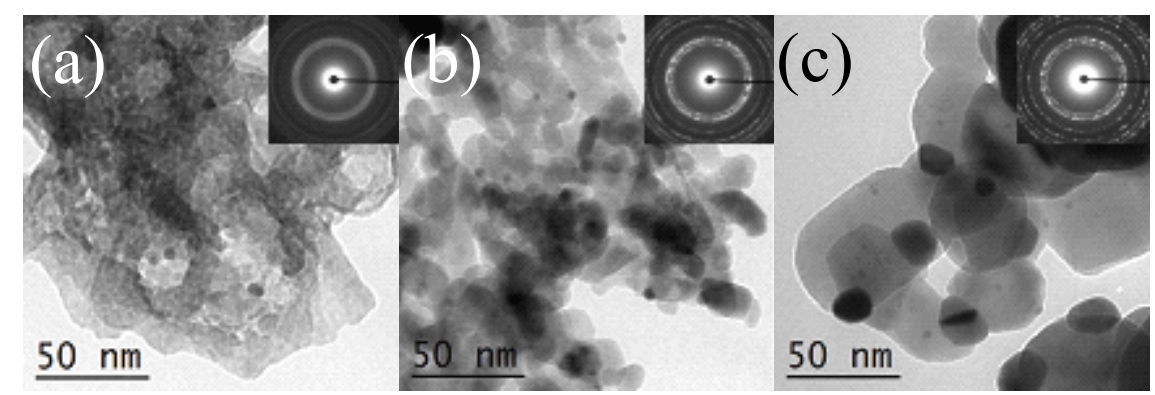

FIG. 2. BF images and SAD patterns showing the morphology of the $\mathrm{ZnO}$ support as a function of calcination treatment: (a) dried only, (b) calcined at $300^{\circ} \mathrm{C}$, and (c) at $400^{\circ} \mathrm{C}$

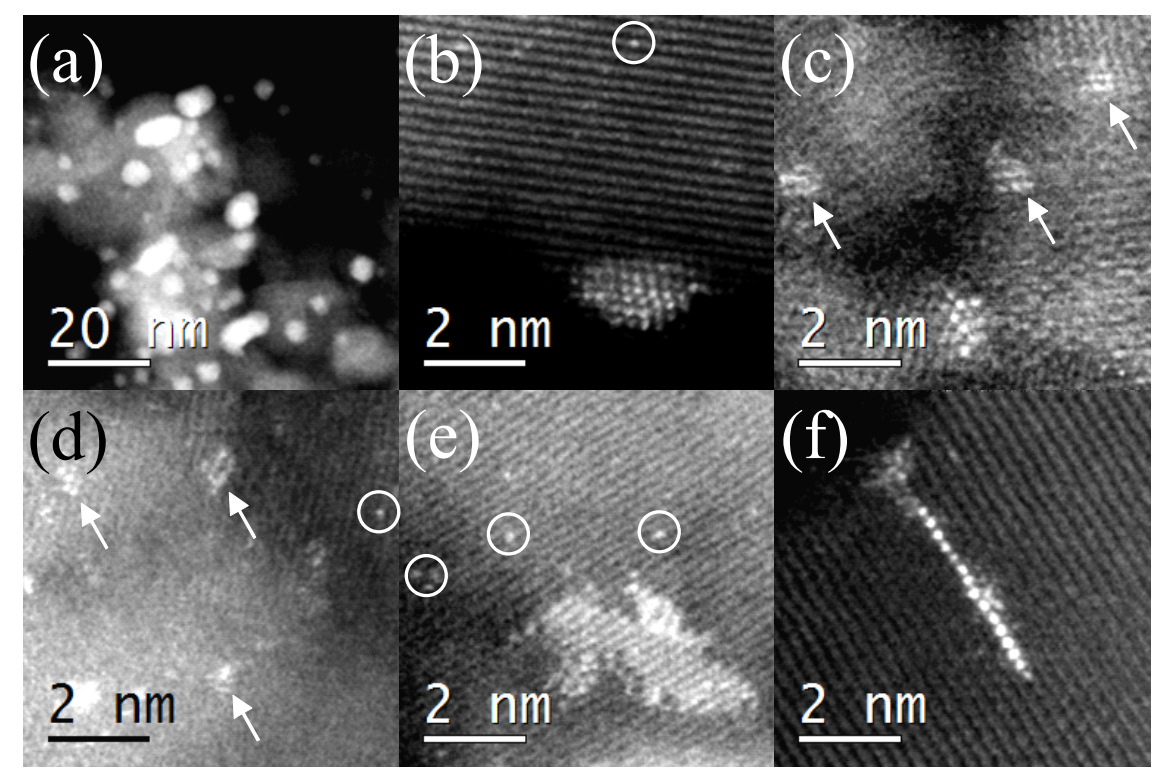

FIG. 3. Aberration-corrected STEM-HAADF images showing the various Au species co-existing on the ZnO support; (a), (b) 3-dimensional Au nano-particles; (c), (d) sub-nm Au clusters (white arrows) and isolated $\mathrm{Au}$ atoms (white circles); (e) ordered monolayer Au rafts and isolated Au atoms and (f) linear stripes of $\mathrm{Au}$. 